\title{
Serrated Lesion of the Mouse Intestinal Tract
}

National Cancer Institute

\section{Source}

National Cancer Institute. Serrated Lesion of the Mouse Intestinal Tract. NCI Thesaurus.

Code C107673.

A large intestinal glandular mucosal lesion in the mouse characterized by epithelial

infoldings and ectopic crypt formation. 